\title{
Gestão Participativa: o caminho para qualidade
}

Recebido em 04.12.2015. Aprovado em 20.12.2015 Avaliado pelo sistema double blind review

\author{
Maria Isabel Machado Ferraz \\ isabelmferraz@yahoo.com.br \\ Escola Amélia dos Santos Junqueira - Ribeirão Preto - SP - Brasil
}

\section{Resumo}

O processo de ensino e aprendizagem é permeado por vários aspectos: o envolvimento dos professores com o trabalho pedagógico; dos alunos com a própria aprendizagem e a relação entre estes dois atores em prol de um mesmo objetivo. Quando isso não ocorre o produto da escola fica deficitário e é manifestado pelos baixos resultados nas avaliações externas. Esses resultados revelam que as aprendizagens mínimas necessárias não ocorreram, ou seja a escola não está cumprindo com sua função social.

A proposta desse plano é proporcionar um envolvimento dos alunos, professores e funcionários para um mesmo objetivo: a qualidade do trabalho da escola, visando acolher e valorizar todos em suas responsabilidades e atividades e em prol do principal serviço da escola que é a aprendizagem dos seus alunos.

Propomos a construção coletiva de metas de qualidade e ações para cada segmento de atuação da escola visando garantir e sempre aumentar a satisfação do usuário e cliente. Com isso oportunizaremos outras formas de contato, acesso e monitoramento das aprendizagens dos alunos, por meio das tecnologias e materiais pedagógicos voltados para a mobilização dos mesmos em prol da própria aprendizagem e também, para utilização nas turmas de reforço escolar, visando estratégias mais eficazes e eficientes no propósito de recuperação das defasagens de aprendizagem.

Diante do exposto o plano de empreendimento tem como objetivos estratégicos: implementar o aprimoramento constante da qualidade dos serviços prestados em todos os segmentos da escola, consolidar o envolvimento do aluno com a própria aprendizagem e garantir que as estratégias de recuperação de aprendizagem sejam efetivas recuperando de fato os alunos em suas dificuldades.

Para sua implementação o valor solicitado de $R$ \$ $30.191,43$ será utilizado na melhoria necessária da infraestrutura, contratação de serviços de informática para plataforma de comunicação e estudo e treinamento dos profissionais que farão uso destas tecnologias, bem como formação continuada dos professores na busca de variadas estratégias e metodologias de trabalho para que a aprendizagem dos alunos efetivamente ocorra.

Palavras-chaves: Plano de Empreendimento. Empreendedorismo e Educação. Gestão participativa. 


\section{Caracterização da Escola}

A Escola Amélia dos Santos Junqueira, localizada em Ipiranga, São José do Rio Preto (SP), foi fundada em 1964 e atende ao Ensino Fundamental II (6o ao 9o ano ). A escola tem como missão "promover uma educação de qualidade, formando um cidadão capaz de respeitar e conviver em sociedade, com foco no aprimoramento das habilidades e competências dos estudantes direcionadas ao mundo do trabalho e ao exercício da cidadania", e a visão de "ser reconhecida como escola de excelência, estando entre as melhores classificadas pelo IDEB na cidade até o ano de 2021; capaz de preparar e estimular a continuação dos estudos, o trabalho em equipe e atitude empreendedora com autonomia na construção do conhecimento."

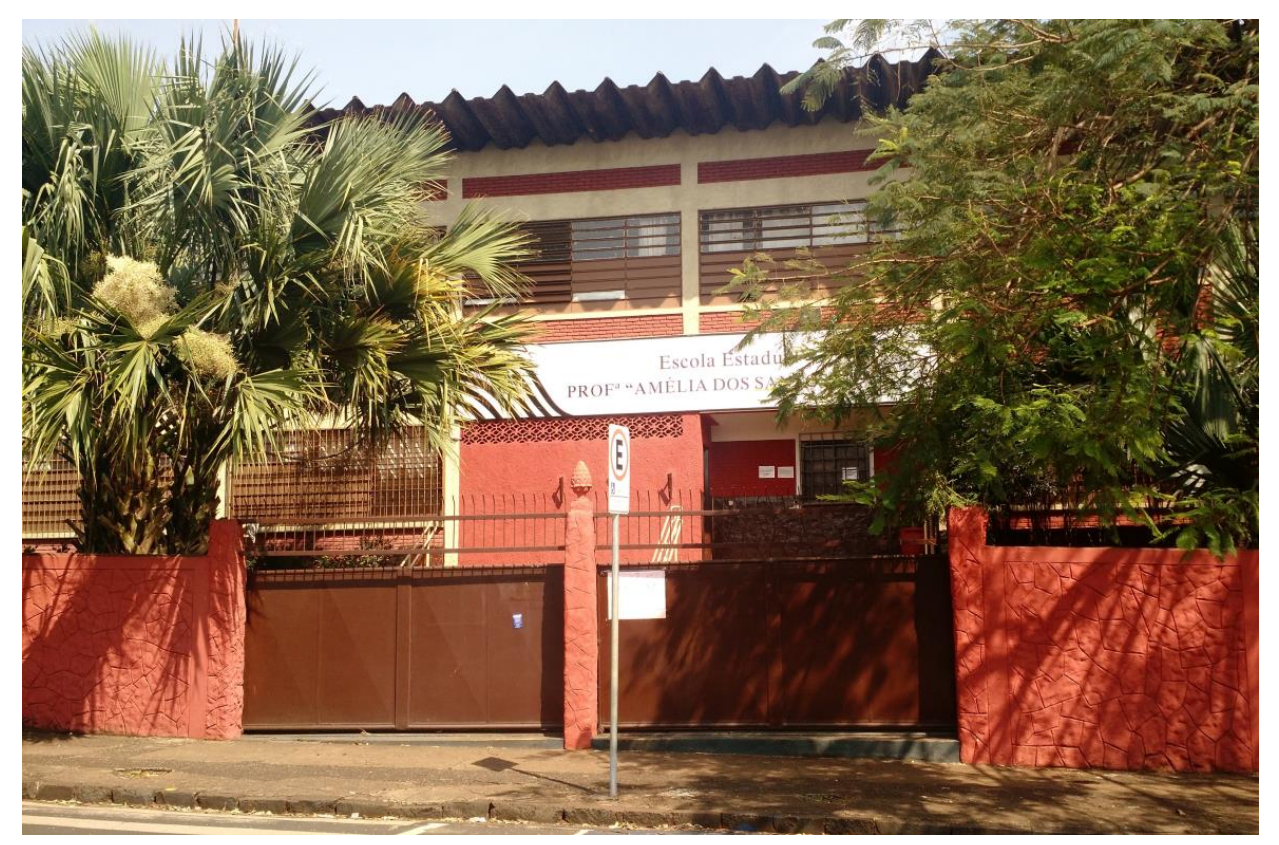

\section{Instalações}

A escola é grande e possui vários espaços, porém antigos. Alguns em bom estado de conservação e outros que necessitam de reforma. Decidiu-se priorizar as reformas e ampliações nos espaços internos que estavam em situação mais crítica, que são: dez salas de aula, uma sala de leitura (biblioteca), um laboratório de informática, sala dos professores, da direção escolar, coordenação pedagógica todos já reformados.

Os espaços externos, apesar de grandes precisam de alguns reparos, que são: quadra descoberta, pátio coberto e descoberto. Temos ainda uma secretaria, cozinha que não precisam de reforma. Os alunos utilizam o pátio coberto como refeitório nos horários de refeições.

O quadro a seguir apresenta a relação dos acontecimentos mais relevantes para a evolução da escola, desde a fundação até hoje.

\begin{tabular}{|l|l|}
\hline Ano & Acontecimentos relevantes \\
\hline 1964 & Fundação da escola \\
\hline 1976 & Inauguração do novo prédio \\
\hline 1977 & Mudança de Prédio no mesmo bairro \\
\hline 2002 & Início da desativação dos 10 anos do fundamental \\
\hline 2003 & Início das matrículas para o ensino fundamental II (6o ano) \\
\hline & \\
\hline
\end{tabular}




\begin{tabular}{|l|l|}
\hline 2004 & Início das Obras de ampliação de salas de aula \\
\hline 2006 & Desativação completa do ensino fundamental I \\
\hline 2007 & Implantação do Ensino Fundamental II completa \\
\hline 2015 & Atendimento do Ensino Fundamental II \\
\hline
\end{tabular}

\section{Professores e funcionários}

A equipe é formada por 14 professores, distribuídos da seguinte forma:

\begin{tabular}{|l|c|}
\hline Disciplina / Área & Quant. de professores \\
\hline Língua Portuguesa & 2 \\
\hline Matemática & 2 \\
\hline Arte & 1 \\
\hline Educação Física & 1 \\
\hline História & 2 \\
\hline Geografia & 2 \\
\hline Ciências & 1 \\
\hline Inglês & 2 \\
\hline Reforço Escolar (contraturno) & 1 \\
\hline
\end{tabular}

Do total de professores, 8 são efetivos e três readaptados que atuam como apoio: um no laboratório de informática, outro na sala de leitura e o terceiro com o reforço escolar. Todos são professores com licenciatura plena no seu componente curricular e temos 4 professores com mestrado.

Além disso, a escola conta com 9 funcionários de apoio, sendo um na secretaria, dois na cozinha, dois na limpeza, dois inspetores escolares, um coordenador pedagógico e o diretor da escola.

\section{Perfil dos alunos}

Os alunos estão distribuídos por séries e turnos da seguinte maneira:

\begin{tabular}{|l|l|l|l|l|l|l|l|l|}
\hline $\begin{array}{l}\text { Série/A } \\
\text { no }\end{array}$ & $\begin{array}{l}\text { Média } \\
\text { de } \\
\text { idade }\end{array}$ & $\begin{array}{l}\text { Total de } \\
\text { alunos }\end{array}$ & No alunos & $\begin{array}{l}\text { No } \\
\text { turmas }\end{array}$ & $\begin{array}{l}\text { No } \\
\text { alunos }\end{array}$ & $\begin{array}{l}\text { No } \\
\text { turmas }\end{array}$ & $\begin{array}{l}\text { No } \\
\text { alunos }\end{array}$ & $\begin{array}{l}\text { No } \\
\text { turmas }\end{array}$ \\
\hline 6o ano & 12,5 & 120 & 60 & 2 & 60 & 2 & - & - \\
\hline 70 ano & 13,5 & 120 & 60 & 2 & 60 & 2 & - & - \\
\hline 80 ano & 14,5 & 120 & 60 & 2 & 60 & 2 & - & - \\
\hline 90 ano & 15,7 & 122 & 64 & 2 & 58 & 2 & - & - \\
\hline TOTAL & - & 480 & 240 & 8 & 240 & 8 & - & - \\
\hline
\end{tabular}

De acordo com pesquisa aplicada às famílias com o objetivo de traçar um panorama geral do perfil socioeconômico e cultural dos nossos alunos, notamos:

a) a renda média é entre 2 e 3 salários mínimos,

b) atividade de lazer e cinema são pouco frequentes, assim como o hábito de leitura.

c) as famílias são compostas e sua maioria por 5 pessoas. 
d) a maioria mora no bairro e se desloca à pé até a escola.

e) temos aproximadamente $25 \%$ dos alunos que trabalham no outro período dificultando sua participação nas aulas de reforço quando necessário.

Eles apresentam o comportamento típico de adolescente. Sua participação nas atividades propostas pela escola depende muito do quanto se sentirem motivados. Quando há uma proposta que para eles é interessante demonstram envolvimento e participam efetivamente.

As famílias poderiam ser mais participativas. Não observamos uma atuação efetiva junto à atuação dos filhos como estudantes. Acreditam que, por seus filhos estarem "maiores" não é necessário mais um acompanhamento próximo deixando-os mais soltos.

\section{Características do entorno}

O bairro onde a escola está inserida é de periferia, apesar da proximidade com o centro da cidade, porém se trata de uma cidade com mais de 500 mil habitantes com todos os problemas que os grandes centros urbanos apresentam. Esse problemas acentuam-se no bairro, pois há grande incidência de roubos nas ruas, assaltos em casas e comércios e frequentes ataques de furtos a transeuntes idosos.

O meio de transporte mais utilizado é ônibus municipal, com várias linhas que atendem o bairro o que facilita o deslocamento.

Temos no bairro uma Igreja Católica, uma Escola Pública de Ensino Médio, uma Igreja Evangélica, um Posto Policial e na cidade temos uma Escola Técnica (ETEC) para onde alguns de nossos alunos almejam estudar após conclusão do fundamental. Na proximidade da escola há um grande centro comercial com muita circulação de pessoas.

\section{Identificação do Problema e da Oportunidade}

O diagnóstico da Unidade Escolar é o ponto de partida para a identificação do problema, foram observados os resultados das avaliações externas, avaliações internas, por meio de seus relatórios de desempenho e, análise e avaliação da equipe pedagógica.

\section{IDEB - Resultado IDEB para 8a série / 90 ano}

\begin{tabular}{|lc|c|c|c|c|c|c|c|c|c|} 
ANO & 2005 & 2007 & 2009 & 2011 & 2013 & 2015 & 2017 & 2019 & 2021 \\
\hline Metas projetadas & - & - & 3,7 & 3,9 & 4,2 & 4,6 & 4,8 & 5,1 & 5,3 \\
\hline Ideb observado & - & 3,6 & 3,6 & 3,9 & 4,3 & & & & \\
\hline
\end{tabular}

Percebe-se no Ideb Observado que no ano de 2009 a escola iniciou um processo de crescimento dos seus resultados, conseguindo atingir as metas projetadas nos anos de 2011 e 2013 . O crescimento de 2013, em relação a 2011 foi maior do que o de 2011 em relação a 2009. São resultados e conquistas importantes, entretanto tímidas se considerarmos a Missão e Visão desta Instituição.

\section{Avaliação estadual - SARESP 2014}

Distribuição percentual dos alunos avaliados nos níveis de proficiência 
LÍNGUA PORTUGUESA MATEMÁTICA CIÊNCIAS

\begin{tabular}{|l|l|l|l|l|l|l|}
\hline Níveis de Proficiência & $7^{\circ}$ ano & $9^{\circ}$ ano & $7^{\circ}$ ano & $9^{\circ}$ ano & $7^{\circ}$ ano & $9^{\circ}$ ano \\
\hline Abaixo do Básico & 23,2 & 23,8 & 39,2 & 26,2 & 33,2 & 28,5 \\
\hline Básico & 39,9 & 59,7 & 36,0 & 56,7 & 35,7 & 49,3 \\
\hline Adequado & 27,3 & 14,9 & 19,4 & 15,1 & 28,4 & 19,8 \\
\hline Avançado & 9,7 & 1,7 & 5,4 & 2,0 & 2,7 & 2,5 \\
\hline Média Geral da Escola & 210,1 & 233,6 & 216,1 & 253,9 & 226,3 & 255,9 \\
\hline
\end{tabular}

Podemos observar que, a maioria dos alunos da escola estão no nível de proficiência Básico nos três componentes curriculares, exceto Matemática 70 ano.

Estes resultados nos levam a refletir que a escola precisa de uma atuação efetiva voltada para 0 deslocamento dos alunos para o nível acima, pois o mínimo esperado é a maioria dos alunos no Nível Adequado. Outro aspecto a considerar é o trabalho realizado ao longo dos anos, pois observamos que os resultados dos alunos do 90 ano são piores do que do 70 ano que nos conduz à conclusão de que o resultado final do trabalho da escola não está bom. $E$ ainda investigar porque os alunos do 70 ano apresentam uma porcentagem mais alta no nível abaixo do básico.

Avaliações e relatórios internos

Tabela com os resultados das avaliações internas realizadas no ano de 2014

\begin{tabular}{|c|c|c|c|c|c|c|c|}
\hline Série/Ano & $\begin{array}{l}\text { Matriculas } \\
\text { iniciais }\end{array}$ & Evasão & Transf. & $\begin{array}{l}\text { Matriculas } \\
\text { finais }\end{array}$ & Disciplinas & Aprov. & Reprov. \\
\hline \multirow{8}{*}{$6^{\circ}$ ano } & \multirow{8}{*}{130} & \multirow{8}{*}{-} & \multirow{8}{*}{10} & \multirow{8}{*}{120} & Português & 82 & 38 \\
\hline & & & & & Matemática & 86 & 34 \\
\hline & & & & & História & 84 & 36 \\
\hline & & & & & Geografia & 83 & 37 \\
\hline & & & & & Ciências & 86 & 34 \\
\hline & & & & & L. Estrangeira & 85 & 35 \\
\hline & & & & & Ed. Física & 86 & 34 \\
\hline & & & & & Artes & 86 & 34 \\
\hline \multirow{8}{*}{$7^{\circ}$ ano } & \multirow{8}{*}{140} & \multirow{8}{*}{5} & \multirow{8}{*}{15} & \multirow{8}{*}{120} & Português & 81 & 39 \\
\hline & & & & & Matemática & 85 & 35 \\
\hline & & & & & História & 83 & 37 \\
\hline & & & & & Geografia & 82 & 38 \\
\hline & & & & & Ciências & 85 & 35 \\
\hline & & & & & L. Estrangeira & 84 & 36 \\
\hline & & & & & Ed. Física & 85 & 35 \\
\hline & & & & & Artes & 85 & 35 \\
\hline
\end{tabular}




\begin{tabular}{|c|c|c|c|c|c|c|c|}
\hline \multirow{8}{*}{$8^{\circ}$ ano } & \multirow{8}{*}{145} & \multirow{8}{*}{15} & \multirow{8}{*}{8} & \multirow{8}{*}{122} & Português & 73 & 49 \\
\hline & & & & & Matemática & 74 & 48 \\
\hline & & & & & História & 74 & 48 \\
\hline & & & & & Geografia & 75 & 47 \\
\hline & & & & & Ciências & 80 & 42 \\
\hline & & & & & L. Estrangeira & 77 & 45 \\
\hline & & & & & Ed. Física & 80 & 42 \\
\hline & & & & & Artes & 80 & 42 \\
\hline \multirow{8}{*}{$9^{\circ}$ ano } & \multirow{8}{*}{152} & \multirow{8}{*}{23} & \multirow{8}{*}{12} & \multirow{8}{*}{117} & Português & 70 & 47 \\
\hline & & & & & Matemática & 71 & 46 \\
\hline & & & & & História & 71 & 46 \\
\hline & & & & & Geografia & 72 & 45 \\
\hline & & & & & Ciências & 77 & 40 \\
\hline & & & & & L. Estrangeira & 74 & 43 \\
\hline & & & & & Ed. Física & 77 & 40 \\
\hline & & & & & Artes & 77 & 40 \\
\hline
\end{tabular}

A média de reprovação da escola é $30 \%$, sendo que 60 e 70 anos com índices menores do que o 80 e 90 anos.

Esta mesma situação se repete em relação aos índices de evasão e transferência ou seja, com o decorrer dos anos aumenta-se o número de alunos evadidos e transferidos para outras escolas.

Aplicamos uma pesquisa descritiva com os alunos da escola, visando coletar mais dados específicos sobre 0 trabalho pedagógico realizado.

A amostra probabilística foi definida com uma margem de erro de $10 \%$ e, portanto aplicamos esta pesquisa em 82 alunos distribuídos nas 16 turmas. Antes da aplicação da pesquisa, realizamos uma reunião com a equipe docente para esclarecer o propósito desta e apresentamos o questionário para conhecimento. Os alunos, público alvo foram orientados por meio dos representantes de classe que tiveram como tarefa apresentar em sua turma a proposta da pesquisa e verificar os candidatos à participação.

$\mathrm{O}$ questionário da pesquisa encontra-se em anexo. $\mathrm{E}$ abaixo segue o gráfico com seus resultados.

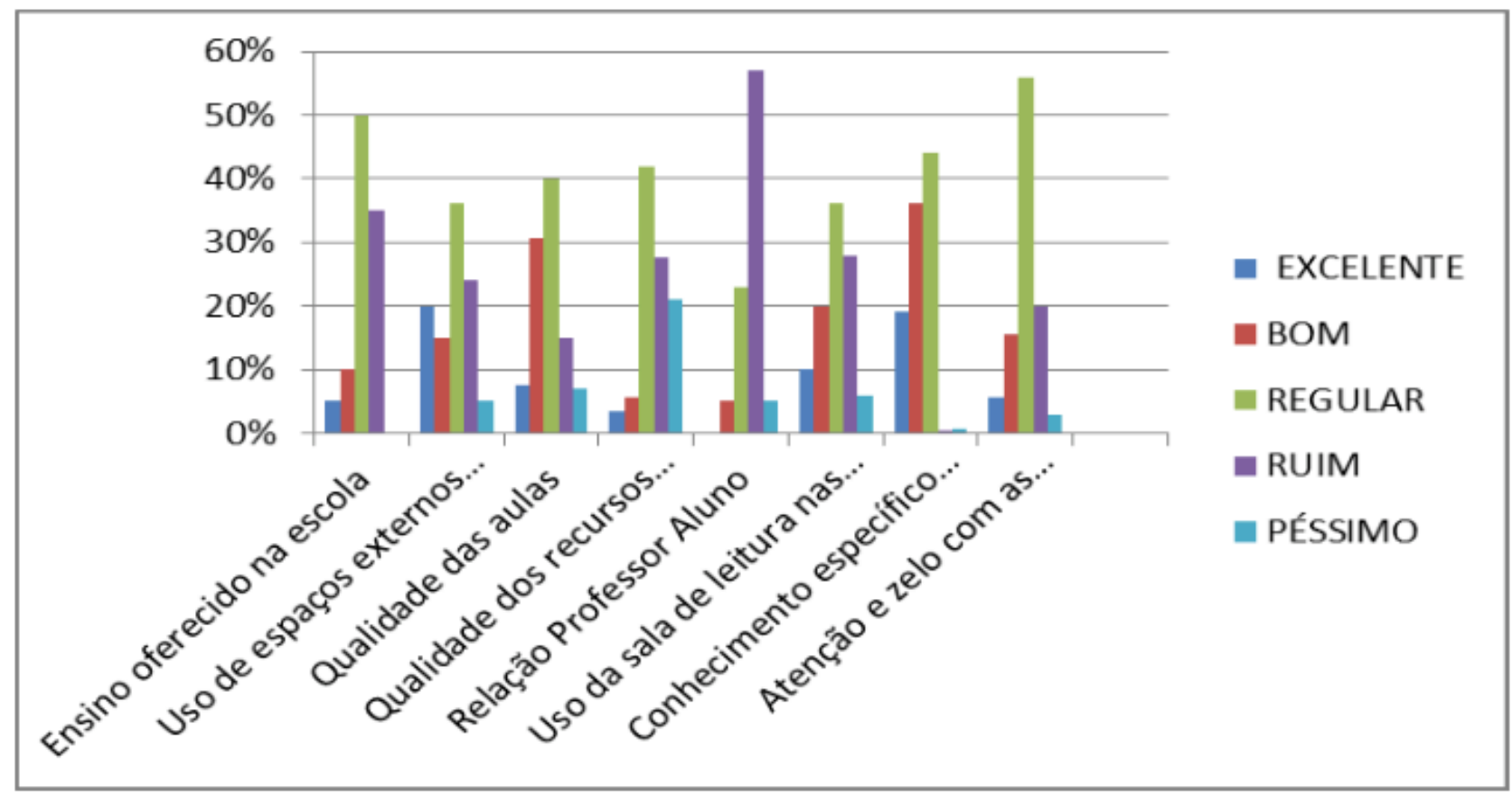


A equipe docente avalia os alunos com rigor e pouca paciência. Descrevem os alunos como preguiçosos e desinteressados. Relatam o desgaste diário com a cobrança das tarefas e lições de casa. Relatam ainda que os alunos não dão importância para seus estudos e tampouco para seus resultados, notas e que alguns alunos demonstram não se preocuparem com uma possível reprova quando questionados sobre seus estudos.

\section{Principais problemas identificados}

Os resultados dos processos avaliativos internos confirmam a hipótese levantada pelos resultados do SARESP, onde revela-se que o produto desta escola não está bom. 0 crescimento do aluno ao longo dos quatro anos nesta unidade diminui gradativamente.

Os problemas abaixo citados contribuem para esse resultado baixo:

PROBLEMA 1 - Família pouco participativa

As famílias delegam toda a ação de educar para a escola e não acompanham o processo de formação de seus filhos. Este comportamento não valida as ações da escola junto aos alunos e reforçam certo desrespeito pelos profissionais da escola.

PROBLEMA 2 - Entorno da escola com a presença do crime

A região da escola é de risco social e precisamos de uma participação mais efetiva das famílias como parceiras da escola na formação desses adolescentes. Quando o jovem envolve-se em algo que the traz um sentido ele não corre risco de se envolver com drogas ou outras transgressões.

PROBLEMA 3 - Alunos não se envolvem nos estudos

Os alunos são pouco participativos em relação ao cumprimento de prazos, de realização de tarefas, trabalhos, ausências em provas, entrega de pesquisas, etc. Esta situação gera constantes conflitos na relação Professor e Aluno, afastando-os de uma relação afetiva pautada no respeito, apreço e admiração, comprometendo assim a qualidade do processo de ensino e aprendizagem.

PROBLEMA 4 - Relação interpessoal entre Professores e Alunos.

Não é observada uma postura de acolhimento e entendimento da realidade dos alunos para que seja possível pensar a melhor forma de intervir no seu desenvolvimento. As ações dos professores permanecem na esfera de cobranças do comportamento esperado para as aulas e cumprimento das tarefas dadas.

Este aspecto impacta diretamente no processo de ensino e aprendizagem, posto que para tal é necessária um relação de afetividade, respeito e confiança, segundo Wallon.

PROBLEMA 5 - Inexistência de ações efetivas de recuperação da aprendizagem.

Observa-se que os professores não refletem sobre a melhor forma de recuperação dos alunos com dificuldades de aprendizagem. Justificam os resultados baixos nas avaliações internas e externas no comportamento, ou melhor, na falta de comportamento dos alunos nas aulas.

Um aluno que a cada dia percebe que não tem alcance sobre os estudos que são propostos nas aulas tende a se afastar cada vez mais.

Os problemas 3, 4 e 5 estão relacionados, pois ao atuarmos para solucionar um deles, os demais também serão sanados.

Então caberá uma Matiz GUT para priorização entre os Problemas 1, 2 e o três últimos Problemas Agrupados, conforme segue: 


\begin{tabular}{|c|c|c|c|c|c|}
\hline Problemas & G & U & $\mathrm{T}$ & GxUxT & Prioridade \\
\hline Família pouco participativa & 3 & 4 & 4 & 48 & 20 \\
\hline Presença do crime no entorno & 3 & 4 & 4 & 48 & 20 \\
\hline $\begin{array}{l}\text { Pouco envolvimento dos alunos nos } \\
\text { estudos }\end{array}$ & \multirow{3}{*}{5} & \multirow{3}{*}{5} & \multirow{3}{*}{5} & \multirow{3}{*}{125} & \multirow[t]{3}{*}{10} \\
\hline Relações interpessoais Professor/Aluno & & & & & \\
\hline Falta de recuperação de aprendizagem & & & & & \\
\hline
\end{tabular}

\section{Detalhamento do problema}

Utilizou-se o Diagrama de Causa e Efeito para detalhar os problemas agrupados que serão compactados no nome de Relação Improdutiva entre Aluno - Escola - Professor:

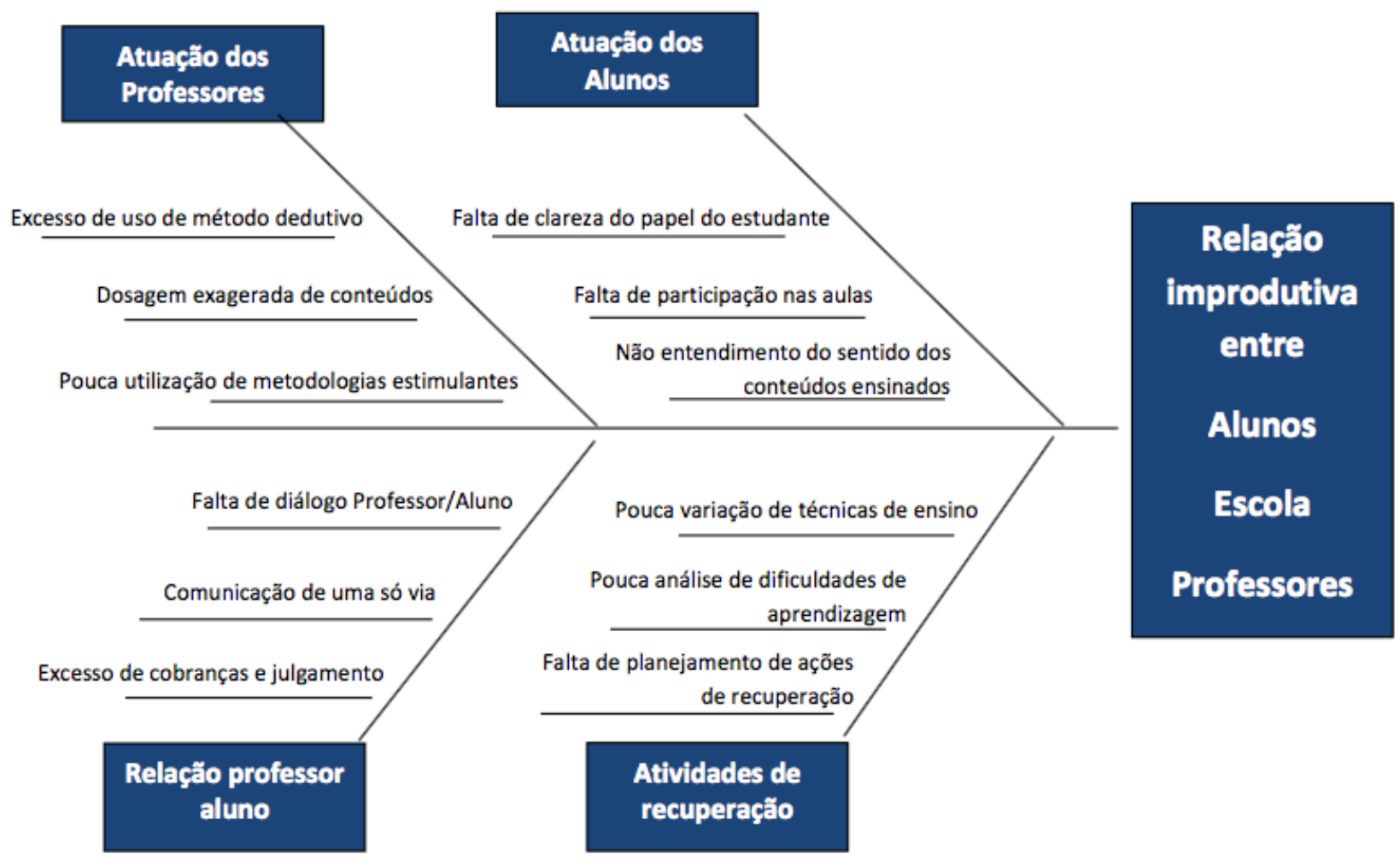

\section{Análise SWOT}

A partir das pesquisas realizadas pela equipe escolar e das discussões sobre o contexto da escola, foi desenvolvida a seguinte Matriz SWOT: 


\begin{tabular}{|c|c|c|}
\hline & Aspectos favoráveis & Aspectos desfavoráveis \\
\hline \multirow[b]{2}{*}{ 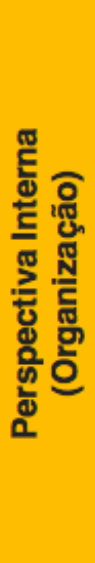 } & FORÇAS & FRAQUEZAS \\
\hline & $\begin{array}{l}\text { - Bom relacionamento interpessoal entre os } \\
\text { funcionários; } \\
\text { - Espaços da escola agradáveis; } \\
\text { - Inspetores de alunos comprometidos; } \\
\text { - Limpeza impecável; } \\
\text { - Bom relacionamento entre Coordenador } \\
\text { Pedagógico e Professores; }\end{array}$ & $\begin{array}{l}\text { - Professores sem clareza do trabalho } \\
\text { pedagógico; } \\
\text { - Professores com dificuldade de lidar com } \\
\text { conflitos; } \\
\text { - Funcionários se unem em corporativismo; } \\
\text { - Dependência de atitudes da gestão para } \\
\text { todas as situações. }\end{array}$ \\
\hline \multirow[b]{2}{*}{ 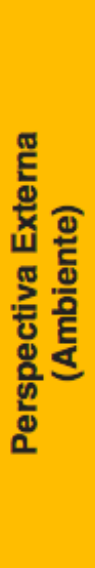 } & OPORTUNIDADES & AMEAÇAS \\
\hline & $\begin{array}{l}\text { - Projeto Mais Educação; } \\
\text { - PNAIC - formação para professores } \\
\text { alfabetizadores; } \\
\text { - Parcerias com Igrejas; } \\
\text { - Parcerias com a ETEC; } \\
\text { - Parcerias com estabelecimentos } \\
\text { comerciais do bairro. }\end{array}$ & $\begin{array}{l}\text { - Presença de tráfico de drogas; } \\
\text { - Aliciamento de jovens para o crime; } \\
\text { - Situação socioeconômica da cidade e das } \\
\text { famílias; } \\
\text { - Ociosidade dos alunos no período } \\
\text { contrário ao de aula. }\end{array}$ \\
\hline
\end{tabular}

Analisando sob a perspectiva interna de organização podemos perceber que temos mais forças do que fraquezas e na perspectiva externa do ambiente temos mais oportunidades do que ameaças.

Esta situação apresentada pela Matriz SWOT demonstra grande potencial de superação dos problemas apontados anteriormente, apesar deles serem de grande porte e dificuldade.

Ações corretivas

Visando preparar a organização para o desenvolvimento do projeto, no intuito de combater as fraquezas e reduzir os possíveis impactos das ameaças, foram definidas as seguintes ações:

- Projeto de Formação Pedagógica Continuada no locus da escola tendo o Coordenador Pedagógico como responsável pelo seu desenvolvimento;

- Potencialização das reuniões periódicas com todos os segmentos de funcionários da escola, visando envolve-los em um Projeto Político Pedagógico;

- Formação Continuada em serviço dos funcionários da escola visando desenvolvimento de autonomia para execução de sua função;

- Parceria com o Posto Policial para um maior acompanhamento dos nossos alunos nos momentos de entrada e saída da escola e também no bairro;

- Criação de grupos de estudos para o contraturno das aulas.

\section{Oportunidade identificada}

A ideia central da proposta é envolver alunos, professores e funcionários para um objetivo comum, a melhoria da qualidade dos processos de trabalho e do processo de ensino e aprendizagem da escola, envolvendo a 
todos os citados como corresponsáveis em sua atuação.

Esta proposta solucionará o problema à médio prazo. Serão várias ações reunidas de maneira integrada em torno da ideia central. Espera-se com isso que os alunos passem a agir como sujeitos da própria aprendizagem; que os professores façam uso efetivo de materiais pedagógicos, hardwares, softwares, acervo literário, das tecnologias visando estimular, envolver e garantir outras formas de contato, acesso e monitoramento da aprendizagem dos alunos; e que os funcionários passem a atuar em prol do aprimoramento de seus processos de trabalho visando sempre à qualidade e a excelência e consequentemente melhoria nos resultados de desempenho dos alunos nas avaliações externas e internas.

\section{Detalhamento do produto/serviço elou processo}

Foco do projeto Série ou conjunto de séries beneficiadas: O projeto visa beneficiar todos os anos do ensino fundamental II do 60 ao 90 ano, ou seja todos os alunos da escola.

Disciplina ou conjunto de disciplinas trabalhadas: o projeto envolverá todos componentes curriculares, envolvendo como atores os professores, alunos e funcionários.

\section{Etapas do projeto}

O projeto será composto pelas seguintes etapas:

\section{Etapa 1 - Definindo Metas de Qualidade}

Objetivo: Elaboração coletiva de metas de qualidade em todos os segmentos da escola, visando uma melhora organizacional da rotina diária, envolvendo todos os funcionários, professores e alunos e aprimoramento do processo de trabalho pedagógico da escola.

Impacto na aprendizagem: Com esta primeira etapa, espera-se disparar um processo de reflexão e autoavaliação voltado para o seu papel na rotina da escola por parte especialmente dos alunos e professores.

Atividades a serem realizadas:

\section{Atividade 1.1}

Descrição: Realização de reuniões com cada segmento da escola, que são:
a) Professores e Coordenador pedagógico,
b) Alunos,
c) Secretaria,
d) Inspetores,
e) Limpeza e cozinha

Estas reuniões visam envolver a todos em um movimento de reflexão e construção conjunta, provocando a autoavaliação do seu trabalho e atuação na rotina da escola, sempre com foco na qualidade do serviço prestado no aprimoramento constante do processo pedagógico da escola.

As metas dos segmentos Professores e Alunos deverão ter como foco a melhoria da aprendizagem de todos os alunos da escola.

Será utilizada com todos os segmentos a técnica de criatividade brainstorming reverso, onde partiremos da seguinte pergunta:

v Que ações você poderia fazer para prejudicar a aprendizagem dos alunos? Duração: 12 dias

Recursos necessários: sala de aula que não é utilizada por nenhuma turma, livro ou caderno para o registro de um ata para documentar as produções dos segmentos e dar continuidade na etapa seguinte.

Equipe envolvida: 0 Coordenador Pedagógico e Diretor da Escola serão os principais responsáveis pelo desenvolvimento desta atividade. 


\section{Atividade 1.2}

Descrição: Consolidação e análise dos resultados da atividade anterior, levantados por meio do brainstorming reverso e organização da próxima atividade.

Duração: 3 dias Recursos necessários: caneta, papel, calculadora, computador. Equipe envolvida: Diretor da Escola e Coordenador Pedagógico

\section{Atividade 1.3}

Descrição: Reuniões com cada segmento para socializar o resultado da atividade 1.1 e para transformar 0 que foi levantado em metas necessárias para a qualidade de atuação no seu segmento, tendo como foco a função social da escola que é a aprendizagem dos nossos alunos, visando esclarecer a todos qual sua contribuição para que 0 ensino tenha qualidade. $O$ segmento da equipe docente e coordenação deverão considerar os resultados do IDEB, bem como as distribuição percentual nos níveis de proficiência do SARESP.

\section{Duração: 15 dias}

Recursos necessários: sala de aula que não é utilizada por nenhuma turma, o caderno de ata para documentar as produções dos segmentos e data show para apresentação dos resultados e digitação das propostas. Painéis de divulgação das metas e ações de cada segmento para fixar nos espaços da escola.

Equipe envolvida: O Coordenador Pedagógico e Diretor da Escola serão os principais responsáveis pelo desenvolvimento desta atividade.

\section{Etapa 2 - Organizando as ações}

Objetivo: Elaboração e organização coletiva de ações para o desenvolvimento do projeto, visando atingir as metas estabelecidas na etapa anterior.

Impacto na aprendizagem: Os alunos terão a oportunidade de vivenciar uma situação de exercício da cidadania e de um pensar na coletividade, bem como participar na elaboração de ações e comportamentos que deverá adotar, criando assim o sentimento de corresponsabilidade no próprio processo de aprendizagem.

\section{Atividade 2.1}

Descrição: Cada segmento terá que detalhar as ações que deverão desenvolver para atingir as metas estabelecidas e definir os atores de cada ação. $O$ segmento equipe docente deverá elaborar ações, nas aulas, que visem recuperar as defasagens observadas nos resultados do SARESP e avaliações internas; e ainda estratégias que envolvam os professores readaptados que atuam na biblioteca e laboratório de informática visando ações de recuperação e estudo no período contrário ao das aulas. Nesta atividade os segmentos deverão planejar as ações que realizarão, por meio de um cronograma, definindo prazos e; propor aquelas que dependem da gestão escolar.

\section{Duração: 30 dias}

Recursos necessários: outros funcionários que poderão cobrir o outro segmento para que realizem esta tarefa e material para o registro.

\section{Equipe envolvida:}

a) Coordenador Pedagógico atuará junto ao segmento professores no encaminhamento da tarefa, tendo como parceiros os professores readaptados que atuam na biblioteca e laboratório para inclusão de estratégias de uso das tecnologias para estimular, envolver e garantir outras formas de contato, acesso e monitoramento da aprendizagem dos alunos,

b) Diretor atuará junto aos funcionários responsáveis de cada segmento para garantir o andamento da tarefa (Coordenador Pedagógico, Professores Readaptados, Funcionários dos segmentos),

c) Um funcionário eleito pelo seu grupo junto aos colegas no encaminhamento das tarefas, 
d) Diretor e Coordenador Pedagógico atuarão em conjunto aos alunos representantes de classe para garantir 0 andamento da tarefa junto aos demais alunos

Atividade 2.2

Descrição: Reuniões com cada segmento para ouvir as propostas e finalizar o planejamento das ações considerando a contribuição da gestão e o papel de cada um na execução e no monitoramento do projeto, bem como o levantamento de material necessário para o desenvolvimento do projeto para aquisição.

Duração: 30 dias

Recursos necessários: sala de aula que não é utilizada por nenhuma turma, o caderno de ata para documentar as produções dos segmentos e data show para apresentação dos resultados e digitação das propostas. Painéis de divulgação das ações organizadas por meio de cronograma de todos os segmentos para fixar nos espaços da escola. E ainda planilha com o levantamento dos materiais pedagógicos sugeridos pela equipe docente para uso em sala de aula; hardwares e softwares necessários para o laboratório de informática e acervo literário para a biblioteca, levantados com os professores readaptados.

Equipe envolvida: O Coordenador Pedagógico, Diretor da Escola e Professores Readaptados.

\section{Etapa 3 - Desenvolvimento das Ações}

Objetivo: Executar as ações planejadas e monitorá-las, visando garantir o seu cumprimento e adequar se for necessário, tendo como foco sempre as metas estabelecidas coletivamente.

Impacto na aprendizagem: por meio da realização das ações os alunos deverão exercitar um comportamento ativo no seu processo de ensino e aprendizagem e com isso uma tomada de consciência deste percurso, desenvolvendo assim a metacognição e autorregulação do próprio processo.

\section{Atividade 3.1}

Descrição: Cada segmento deverá incorporar no seu dia a dia as ações e atitudes combinadas e planejadas na etapa anterior.

Duração: 60 dias

Recursos necessários: ferramentas de tecnológica do laboratório de informática (hardwares e softwares de estudo, pesquisa e comunicação entre alunos e professores) e da biblioteca (acervo de livros para leitura e pesquisa), cadernos e livros normalmente utilizados nas aulas, material de estudo para as atividades de reforço, caderno de registro do acompanhamento das ações.

Equipe envolvida: Diretor da Escola, Coordenador Pedagógico, Professores, Funcionários e Alunos.

\section{Atividade 3.2}

Descrição: Considerando a necessidade de momentos de parada para analisar e refletir sobre 0 desenvolvimento do projeto, visando a continuidade ou a adequação de alguma estratégia realizaremos reuniões para avaliar e validar ou replanejar as ações como base sempre nas metas estabelecidas. Neste momento Diretor e Coordenador Pedagógico socializam e fazem as intervenções necessárias baseados na observação e registro feitos durante o período de execução.

\section{Duração: 30 dias}

Recursos necessários: sala de aula que não é utilizada por nenhuma turma, o caderno de ata para documentar as reflexões dos segmentos, data show para apresentação dos aspectos observados pela equipe gestora.

Equipe envolvida: O Coordenador Pedagógico e Diretor da Escola.

\section{Atividade 3.3}

Descrição: Continuidade das ações após avaliação na atividade 3.2 e considerando a necessidade de momentos de parada para analisar e refletir sobre o desenvolvimento do projeto, faremos uso das reuniões 
periódicas normalmente realizadas com os segmentos da escola para monitorar os eu desenvolvimento, conforme descrito na atividade anterior.

Duração: 4 meses Recursos necessários: Os mesmos das atividades 3.1 e 3.2

Equipe envolvida: Diretor da Escola, Coordenador Pedagógico, Professores, Funcionários e Alunos.

\section{Etapa 4 - Monitoramento e Avaliação dos Resultados}

Objetivo; Coletar, armazenar e divulgar as informações de desempenho do projeto, tendo como foco as metas estabelecidas e reorganizar, replanejando se necessário a próxima etapa de desenvolvimento do projeto.

Impacto na aprendizagem: verificação do desempenho dos alunos por meio dos indicadores (avaliações internas e externas).

\section{Atividade 4.1}

Descrição: Coleta e análise das informações fornecidas pelos indicadores de qualidade de cada segmento. Eles serão agrupados conforme segue:

a) Professores e Alunos - Avaliações Internas e Externas,

b) Funcionários da secretaria, cozinha, limpeza e inspetores - Pesquisa de Satisfação do Público Interno, usuários dos serviços.

Duração: 30 dias

Recursos necessários: Calculadora, computador, internet, Datashow, folhas para aplicação da pesquisa de satisfação.

Equipe envolvida: Diretor Escolar e Coordenador Pedagógico

\section{Atividade 4.2}

Descrição: Divulgação e avaliação conjunta dos resultados e reorganização das ações visando a melhoria contínua dos resultados, por meio das reuniões periódicas realizadas com cada segmento.

Duração; 30 dias

Recursos necessários: sala de aula que não é utilizada por nenhuma turma, o caderno de ata para documentar as produções dos segmentos e data show para apresentação dos resultados e digitação das propostas.

Equipe envolvida: Diretor Escolar e Coordenador Pedagógico.

\section{Atividade 4.3}

Descrição: Continuidade das ações após avaliação na atividade 4.2 com estratégias já estabelecidas de monitoramento e acompanhamento desse desenvolvimento pela equipe gestora.

Duração: 2 anos

Recursos necessários: Já descritos anteriormente para o desenvolvimento das ações de cada segmento e para os momentos de análise e avaliações do andamento do projeto.

Equipe envolvida: Diretor da Escola, Coordenador Pedagógico, Professores, Funcionários e Alunos.

\section{Atividade 4.4}

Descrição: Momentos pontuais de reuniões para analisar e refletir sobre o desenvolvimento do projeto, faremos uso das reuniões periódicas normalmente realizadas com os segmentos da escola.

Periodicidade: Meses do ano 2 - Agosto, Outubro e Fevereiro Meses do ano 3 - Maio, Agosto e Novembro

Recursos necessários: sala de aula que não é utilizada por nenhuma turma, o caderno de ata para 
documentar as reflexões dos segmentos, data show para apresentação dos aspectos observados pela equipe gestora.

Equipe envolvida: Diretor da Escola, Coordenador Pedagógico, Professores, Funcionários e Alunos.

\section{Casos de sucesso}

Nome do Projeto: Incentivo à leitura Nome da organização: Escola Classe 03 Local: Paranoá - Distrito Federal Período em que foi realizado: Duração do Projeto Político Pedagógico da Unidade Escolar

Breve relato do contexto anterior ao projeto: a degradação do ensino gratuito no cenário nacional dissemina a crença que os estudantes terão uma formação deficiente, especialmente nos primeiros anos de vida escolar. No ano de 2005 o IDEB era 3,6 - abaixo da meta projetada. Em 2007 esse resultado saltou para 4,5 acima da meta projetada.

Principais atividades desenvolvidas: Mesmo sem receber verba extra do governo, trabalhando contra todas as dificuldades, ainda assim encontraram a excelência por meio do comprometimento de gestores e professores. 0 projeto político pedagógico da escola tem uma única meta: 0 incentivo à leitura. Os alunos devem saber interpretar uma diversidade de gêneros textuais, é o aprendizado por meio da provocação dos estudantes e estímulo à leitura que desenvolvem autonomia. Não é somente um professor copiando a matéria no quadro. Os alunos leem em média um livro por mês.

Resumo dos principais resultados alcançados: A escola, mesmo instalada em uma cidade periférica e pobre, alcançou nota 6,2 (em 2009) e 6,7 (a partir de 2011); similar ao índice médio do ensino privado no DF, de 6,8. Entre 783 alunos atendidos, está Luana Cristina Damasceno, 10 anos que em oito meses leu nove publicações.

Fonte: Receitas de Sucesso nas Escolas Públicas - www.correiobraziliense.com.br

Nome do Projeto: Metas Educacionais Nome da organização: Escola Classe 39 Local: Taquatinga - Distrito Federal Período em que foi realizado: Inicialmente na implantação do novo modelo de gestão Breve relato do contexto anterior ao projeto: a degradação do ensino gratuito no cenário nacional dissemina a crença que os estudantes terão uma formação deficiente, especialmente nos primeiros anos de vida escolar. No ano de 2005 o IDEB era 5,0 - abaixo da meta projetada. Em 2007 a escola conseguiu superar a meta projetada IDEB e em 2011 atingiu $6,8$.

Principais atividades desenvolvidas: Trabalhando contra todas as dificuldades, encontraram a excelência por meio do comprometimento de gestores e professores. O projeto pedagógico é feito a longo prazo e, não, anualmente. $O$ diagnóstico de determinados erros acontece periodicamente, impedindo a repetição deles no futuro. As experiências com questionários respondidos por professores, pedagogos, pais e alunos causam uma reflexão, que, posteriormente, é transformada em ação.

Resumo dos principais resultados alcançados: 0 IDEB da instituição é 6,8, enquanto a avaliação de outros centros de ensino da mesma cidade não passa de 4,0. Fonte: Receitas de Sucesso nas Escolas Públicas www.correiobraziliense.com.br

\section{Novidade trazida pelo projeto}

Estes projetos foram inspiradores para a organização deste, entretanto 0 diferencial é que 0 foco será 0 envolvimento de todos em busca do aprimoramento do produto da escola.

Inicialmente a conscientização de todos os atores que convivem no espaço escolar diariamente de que seu papel tem importância para o produto da escola e que esse produto é a aprendizagem de todos os nossos alunos. Mesmo que a contribuição não seja direta ela existe. E finalmente o estabelecimento de metas de cada um para que se sinta corresponsável pelo processo e que a qualidade deste gerará um bom produto. A originalidade deste projeto consiste em investir no protagonismo dos profissionais que atuam na escola e principalmente dos alunos em um processo de participação efetiva nas tomadas de decisão, organização e reorganização de ações. 


\section{Cronograma de execução}

Constam deste cronograma somente os meses que não terão recesso e/ou férias

\begin{tabular}{|c|c|c|c|c|c|c|c|c|c|c|c|c|c|c|c|}
\hline \multirow{2}{*}{\multicolumn{2}{|c|}{ Atividades }} & \multicolumn{5}{|c|}{ Ano 1} & \multicolumn{5}{|c|}{ Ano 2} & \multicolumn{4}{|c|}{ Ano 3} \\
\hline & & \multirow[t]{2}{*}{$\begin{array}{l}\text { Fev/ } \\
\text { Mar }\end{array}$} & \multirow[t]{2}{*}{$\begin{array}{l}\text { Abr/ } \\
\text { Mail }\end{array}$} & \multirow[t]{2}{*}{$\begin{array}{l}\text { Jun- } \\
\text { Ago }\end{array}$} & \multirow[t]{2}{*}{$\begin{array}{l}\text { Set/ } \\
\text { Out }\end{array}$} & \multirow[t]{2}{*}{$\begin{array}{l}\text { Nov } \\
\text {-Fev }\end{array}$} & \multirow[t]{2}{*}{$\begin{array}{c}\text { Mar / } \\
\text { Abr }\end{array}$} & \multirow[t]{2}{*}{$\begin{array}{c}\text { Mai / } \\
\text { Jun }\end{array}$} & \multirow[t]{2}{*}{$\begin{array}{l}\text { Ago/ } \\
\text { Set }\end{array}$} & \multirow[t]{2}{*}{$\begin{array}{l}\text { Set / } \\
\text { Out }\end{array}$} & \multirow[t]{2}{*}{$\begin{array}{l}\text { Nov } \\
- \\
\text { Fev }\end{array}$} & \multirow[t]{2}{*}{$\begin{array}{l}\text { Mar- } \\
\text { Abr }\end{array}$} & \multirow[t]{2}{*}{$\begin{array}{l}\text { Maly } \\
\text { Jun- }\end{array}$} & \multirow[t]{2}{*}{$\begin{array}{l}\text { Ago/ } \\
\text { Set }\end{array}$} & \multirow[t]{2}{*}{$\begin{array}{l}\text { Out- } \\
\text { Nov }\end{array}$} \\
\hline \multirow{3}{*}{ Etapa 1} & Ativ. 1.1 & & & & & & & & & & & & & & \\
\hline & Ativ. 1.2 & & & & & & & & & & & & & & \\
\hline & Ativ. 1.3 & & & & & & & & & & & & & & \\
\hline \multirow{2}{*}{ Etapa 2} & Ativ. 2.1 & & & & & & & & & & & & & & \\
\hline & Ativ. 2.2 & & & & & & & & & & & & & & \\
\hline \multirow{3}{*}{ Etapa 3} & Ativ. 3.1 & & & & & & & & & & & & & & \\
\hline & Ativ. 3.2 & & & & & & & & & & & & & & \\
\hline & Ativ. 3.3 & & & & & & & & & & & & & & \\
\hline \multirow{4}{*}{ Etapa 4} & Ativ. 4.1 & & & & & & & & & & & & & & \\
\hline & Ativ. 4.2 & & & & & & & & & & & & & & \\
\hline & Ativ. 4.3 & & & & & & & & & & & & & & \\
\hline & Ativ. 4.4 & & & & & & & & & & & & & & \\
\hline
\end{tabular}

\section{Gestão Estratégica}

Objetivos estratégicos

\begin{tabular}{|l|l|l|l|}
\hline Objetivos & Metas & Indicadores & Acompanhamento \\
\hline & $\begin{array}{l}\text { Aumentar em 10\% } \\
\text { o nível de } \\
\text { satisfação dos } \\
\text { usuários dos } \\
\text { serviços de } \\
\text { merenda escolar } \\
\text { em cada ano do } \\
\text { projeto. }\end{array}$ & $\begin{array}{l}\text { Satisfação dos } \\
\text { usuários deste } \\
\text { serviço (alunos) }\end{array}$ & $\begin{array}{l}\text { Reuniões trimestrais para avaliação } \\
\text { e análise dos resultados da } \\
\text { pesquisa de satisfação visando } \\
\text { reorganização do serviço, caso } \\
\text { necessário. }\end{array}$ \\
\cline { 2 - 4 } $\begin{array}{l}\text { Implementar } \\
\text { processos de trabalho } \\
\text { para aprimoramento } \\
\text { constante da } \\
\text { qualidade dos serviços } \\
\text { de cada segmento da } \\
\text { unidade escolar }\end{array}$ & $\begin{array}{l}\text { Aumentar em 10\% } \\
\text { o nível de } \\
\text { satisfação dos } \\
\text { usuários dos } \\
\text { serviços de limpeza } \\
\text { dos espaços } \\
\text { escolares em cada } \\
\text { ano do projeto. }\end{array}$ & $\begin{array}{l}\text { Satisfação dos } \\
\text { alunos e demais } \\
\text { funcionários da } \\
\text { escola. }\end{array}$ & $\begin{array}{l}\text { Reuniões trimestrais para avaliação } \\
\text { e análise dos resultados da } \\
\text { pesquisa de satisfação visando } \\
\text { reorganização do serviço, caso } \\
\text { necessário. }\end{array}$ \\
\cline { 2 - 4 } & $\begin{array}{l}\text { Aumentar em 10\% } \\
\text { o nível de } \\
\text { satisfação dos } \\
\text { usuários dos }\end{array}$ & $\begin{array}{l}\text { Satisfação dos } \\
\text { alunos e demais } \\
\text { funcionários da } \\
\text { escola. }\end{array}$ & $\begin{array}{l}\text { Reuniões trimestrais para avaliação } \\
\text { e análise dos resultados da } \\
\text { pesquisa de satisfação visando } \\
\text { reorganização do serviço, caso }\end{array}$ \\
\hline
\end{tabular}




\begin{tabular}{|c|c|c|c|}
\hline & $\begin{array}{l}\text { serviços da } \\
\text { secretaria escolar } \\
\text { em cada ano do } \\
\text { projeto. }\end{array}$ & & necessário. \\
\hline \multirow{3}{*}{$\begin{array}{l}\text { Aumentar o } \\
\text { envolvimento dos } \\
\text { alunos com o próprio } \\
\text { processo de ensino e } \\
\text { aprendizagem }\end{array}$} & $\begin{array}{l}\text { Aumentar o número } \\
\text { de alunos que } \\
\text { utilizam a biblioteca } \\
\text { para estudo e } \\
\text { pesquisa em } 5 \% \text { no } \\
\text { final do primeiro } \\
\text { ano, } 10 \% \text { no final } \\
\text { do segundo e } 15 \% \\
\text { no terceiro. }\end{array}$ & $\begin{array}{l}\text { Número de } \\
\text { empréstimos de } \\
\text { livros e Satisfação } \\
\text { dos alunos e } \\
\text { professores }\end{array}$ & $\begin{array}{l}\text { Reuniões bimestrais com o } \\
\text { professor readaptado para análise } \\
\text { dos indicadores. }\end{array}$ \\
\hline & $\begin{array}{l}\text { Aumentar em } 10 \% \\
\text { o número de } \\
\text { acessos na internet } \\
\text { para informes sobre } \\
\text { tarefas, textos de } \\
\text { sugestão para } \\
\text { estudos e pesquisa } \\
\text { entre professores e } \\
\text { alunos. }\end{array}$ & $\begin{array}{l}\text { Acessos ao blog da } \\
\text { escola, frequência } \\
\text { de utilização do } \\
\text { laboratório de } \\
\text { informática e } \\
\text { satisfação dos } \\
\text { alunos e } \\
\text { professores }\end{array}$ & $\begin{array}{l}\text { Reuniões bimestrais com o } \\
\text { professor readaptado para analise } \\
\text { dos resultados apresentados pelos } \\
\text { indicadores. }\end{array}$ \\
\hline & $\begin{array}{l}\text { Diminuir em } 10 \% \\
\text { números de } \\
\text { ocorrências de } \\
\text { alunos que não } \\
\text { realizam tarefas } \\
\text { solicitadas para as } \\
\text { aulas ao final do } 20 \\
\text { ano e } 20 \% \text { ao final } \\
\text { do terceiro }\end{array}$ & $\begin{array}{l}\text { Número de } \\
\text { ocorrências e } \\
\text { registro de alunos } \\
\text { que não fazem } \\
\text { tarefa. }\end{array}$ & $\begin{array}{l}\text { Reuniões bimestrais com os } \\
\text { professores e coordenador para } \\
\text { avaliação das estratégias adotadas. }\end{array}$ \\
\hline \multirow[t]{2}{*}{$\begin{array}{l}\text { Implementar ação de } \\
\text { recuperação e reforço } \\
\text { das dificuldades de } \\
\text { aprendizagem assim } \\
\text { que detectadas }\end{array}$} & $\begin{array}{l}\text { Reduzir em } 10 \% 0 \\
\text { percentual de } \\
\text { alunos nos níveis } \\
\text { Abaixo do Básico e } \\
\text { Básico e aumentar } \\
\text { em } 10 \% \text { nos níveis } \\
\text { Adequado e } \\
\text { Avançado do } \\
\text { SARESP } 2017 \text { nas } \\
\text { disciplinas } \\
\text { avaliadas. }\end{array}$ & $\begin{array}{l}\text { Simulado com } \\
\text { avaliações similares } \\
\text { ao SARESP, } \\
\text { Resultado da } \\
\text { avaliação externa } \\
\text { SARESP } 2017 .\end{array}$ & $\begin{array}{l}\text { Análise bimestral de habilidades } \\
\text { necessárias. Discussão e avaliação } \\
\text { das ações realizadas com base nas } \\
\text { dificuldades de aprendizagem } \\
\text { observadas nas avaliações } \\
\text { periódicas realizadas pelos } \\
\text { professores. }\end{array}$ \\
\hline & $\begin{array}{l}\text { Aumentar o número } \\
\text { de aprovações } \\
\text { em } 10 \% \text { ao final do } \\
\text { primeiro ano do }\end{array}$ & $\begin{array}{l}\text { Avaliações das } \\
\text { disciplinas e } \\
\text { relatórios de turmas }\end{array}$ & $\begin{array}{l}\text { Controle bimestral do rendimento } \\
\text { das turmas e definição de ações } \\
\text { corretivas para o planejamento } \\
\text { (caso seja necessário), levando em } \\
\text { consideração também o feedback }\end{array}$ \\
\hline
\end{tabular}


projeto; $15 \%$ no

segundo ano e $20 \%$

no terceiro. de alunos e professores.

\section{Continuidade do projeto}

Espera-se que, após aquisição dos materiais pedagógicos e demais recursos levantados pelos próprios professores e funcionários e ainda pelo estímulo e acompanhamento de sua utilização ao longo do projeto, ocorra a incorporação do hábito de uma atuação pela qualidade do serviço prestado.

Este tipo de atuação profissional será reforçado com a manutenção das estratégias de monitoramento e avaliação dos resultados por meio de reuniões periódicas de análise dos resultados apresentados pelos indicadores, com cada segmento da escola, visando o replanejamento de ações quando detectados defasagem no trabalho ou problema a ser resolvido.

\section{Marketing e Comunicação}

\section{Lançamento do projeto}

\section{Gestão Participativa! Venha fazer sua parte!}

Esta será a chamada para todos os funcionários, professores e alunos da escola visando instituir um marketing integrado. Antes de iniciarmos as reuniões para definição das idéias a serem lançadas para os segmentos iniciarem a construção do projeto, iniciaremos com cartazes afixados em todos os lugares da escola visando atender o público interno e também cartazes de divulgação para o público externo (pais e comunidade) no painel externo da escola.

Após o levantamento e compra dos materiais pedagógicos, softwares, hardwares e livros e equipados 0 laboratório de informática, a biblioteca e uma sala de aula que será utilizada para aulas de estudo e reforço escolar realizaremos um evento de apresentação, aos pais e comunidade, desses espaços equipados e a forma de utilização proposta, bem como as estratégias de serviço adotadas pela merenda, limpeza, inspetoria, secretaria, gestão escolar, etc.

Nesta ocasião faremos o lançamento do Blog de divulgação dos resultados das metas atingidas para acompanhamento por todos.

Canais de comunicação e acompanhamento do projeto

\section{Marketing interno}

Os diferentes segmentos da escola terão um grupo no whatzap, onde poderão comunicar-se entre eles e a equipe gestora que fará parte de cada um dos grupos. A função é comunicação interna entre os pares que atuam no mesmo serviço e será utilizado no desenvolvimento das ações planejadas.

Faremos um cadastro de e-mails dos funcionários, professores, alunos e gestão para divulgação e agendamento das ações e os resultados de cada segmento. Este terá uma função mais formal de divulgação interna dos resultados de todos os serviços da escola e será utilizado após aplicação análise dos resultados por meio dos indicadores. Tudo o que for divulgado por email será fixado nos painéis da escola.

Professores, alunos, funcionários e equipe gestora entrará em um grupo do facebook também com a finalidade de divulgação e agendamento das ações e resultados dos diferentes segmentos cuja função será chamada para atuação e divulgar os sucessos, visando sempre disseminar o otimismo, empenho e valorização das conquistas de cada etapa do projeto. Esta divulgação também ocorrerá por meio de painéis que serão afixados em todos os locais da escola. A frequência destes canais será obrigatoriamente quando da divulgação das conquistas identificadas por meio das análises dos indicadores, porém em qualquer momento em que ocorra algo que deve ser evidenciado positivamente este canal será utilizado.

Marketing externo 
A divulgação dos resultados apurados em cada período de avaliação e análise do projeto ocorrerá por meio dos painéis externos (secretaria da escola), do blog, e mala direta aos pais e/ou responsáveis dos alunos.

A divulgação, por meio de email e os painéis terá um foco de apresentação formal dos resultados. Já o youtube e o blog terão como objetivo a divulgação dos sucessos e conquistas de cada segmento.

\section{Parceiros estratégicos}

Participação de profissional de informática.

Nome: Ademar dos Santos - técnico e vendedor de equipamentos de tecnologia e informática do bairro

Realizará palestra para ensinar funcionários e professores a utilizar os recursos do facebook, email, acessar blog, youtube e whatzap.

Terá momento com os professores readaptados que atuam na biblioteca e no laboratório de informática sobre a utilização dos recursos tecnológicos previstos no projeto.

Em contrapartida a escola divulgará esta ação nos meios de comunicação e divulgação internos e externos descritos anteriormente.

Para propor a parceria levaremos o plano de marketing evidenciando as necessidades da escola e as possibilidades de propaganda e divulgação de sua loja.

Oficina de matemática Maria Aparecida Mirando - Professora aposentada da rede estadual de ensino

Realizará oficina aos professores e coordenador pedagógico sobre jogos matemáticos, com o objetivo de estruturar estratégias de trabalho com os alunos para o desenvolvimento de habilidades mentais.

Por meio desta oficina, a escola fornecerá informações e dados para pesquisa de campo que está realizando em sua tese de doutorado.

\section{Divulgação de resultados}

O final de cada ano letivo é momento onde a equipe escolar reúne-se para uma avaliação institucional que visa avaliar as ações realizadas no ano, os projetos bem sucedidos ou não e tomar decisões, ou seja, quais ações serão mantidas, quais reformuladas e quais construídas.

Neste processo caberá a utilização dos resultados das etapas, bem como as análises e ações replanejadas no desenvolvimento do projeto.

A divulgação desses resultados será por meio das estratégias de endomarketing e marketing já descritas. Essa reunião de avaliação institucional servirá para validar cada etapa e atividade desenvolvida do projeto e as etapas e atividades que estão planejadas, bem como um momento a mais destinado ao seu monitoramento pela comunidade interna da escola.

Após essa reunião teremos uma Reunião do Conselho de Escola onde serão apresentados os resultados e as ações replanejadas para validação por todos os envolvidos no trabalho da escola (representantes das comunidades interna e externa) e ainda realizamos a Reunião de Pais e Mestres, visando apresentação dos resultados de aprendizagem dos alunos (boletins, alunos aprovados, reprovados, etc) e serão divulgados também os resultados do projeto até o momento, bem como o posicionamento do Conselho de Escola como informe do andamento do projeto inserido no trabalho cotidiano da escola - ampliação da divulgação para toda a comunidade externa, nosso clientes (os pais e/ou responsáveis). 


\section{Equipe do Projeto}

\section{Equipe interna}

\begin{tabular}{|c|c|c|c|c|}
\hline Cargo & Formação & $\begin{array}{l}\text { Tempo na } \\
\text { escola }\end{array}$ & Experiência anterior & $\begin{array}{c}\text { Responsável } \\
\text { pelas } \\
\text { atividades: }\end{array}$ \\
\hline Direção Escolar & Pedagogia & 3 anos & $\begin{array}{l}\text { Docência e Coordenação } \\
\text { Pedagógica }\end{array}$ & $\begin{array}{l}1.1 / 1.2 / 1.3 \\
2.1 / 2.2 \\
3.1 / 3.2 / 3.3 \\
4.1 / 4.2 / 4.3 / \\
4.4\end{array}$ \\
\hline $\begin{array}{l}\text { Coordenação } \\
\text { Pedagógica }\end{array}$ & $\begin{array}{l}\text { Pedagogia e } \\
\text { Licenciatura em } \\
\text { Português }\end{array}$ & 5 anos & Docência EF I e EF II & $\begin{array}{l}1.1 / 1.2 / 1.3 \\
2.1 / 2.2 \\
3.1 / 3.2 / 3.3 \\
4.1 / 4.2 / 4.3 / \\
4.4\end{array}$ \\
\hline $\begin{array}{l}\text { Professor } \\
\text { (readaptado } \\
\text { biblioteca) }\end{array}$ & $\begin{array}{l}\text { Licenciatura Plena } \\
\text { em Português e } \\
\text { Inglês }\end{array}$ & 22 anos & $\begin{array}{l}\text { Docência de Português e } \\
\text { Inglês }\end{array}$ & $\begin{array}{l}2.1 / 2.2 \\
3.1 / 3.3 \\
4.1 / 4.2 / 4.3 / 4.4\end{array}$ \\
\hline $\begin{array}{l}\text { Professor } \\
\text { (readaptada } \\
\text { informática) }\end{array}$ & $\begin{array}{l}\text { Licenciatura Plena } \\
\text { em Matemática }\end{array}$ & 15 anos & $\begin{array}{l}\text { Docência de Matemática } \\
\text { e Informática }\end{array}$ & $\begin{array}{l}2.1 / 2.2 \\
3.1 / 3.3 \\
4.1 / 4.2 / 4.3 / 4.4 \\
\end{array}$ \\
\hline $\begin{array}{l}\text { Professor } \\
\text { (readaptado 3) }\end{array}$ & $\begin{array}{l}\text { Pedagogia e } \\
\text { Licenciatura em } \\
\text { Ciências }\end{array}$ & 14 anos & Docência EF I e EF II & $\begin{array}{l}2.1 / 2.2 \\
3.1 / 3.3 \\
4.1 / 4.2 / 4.3 / 4.4\end{array}$ \\
\hline $\begin{array}{l}\text { Professor de } \\
\text { História }\end{array}$ & $\begin{array}{l}\text { Licenciatura Plena } \\
\text { em História }\end{array}$ & 8 anos & $\begin{array}{l}\text { Docência de História e } \\
\text { venda de Mídias Digitais }\end{array}$ & $\begin{array}{l}3.1 / 3.3 \\
4.3 / 4.4\end{array}$ \\
\hline Secretário Escolar & Ensino Médio & 18 anos & Secretária de Advogado & $\begin{array}{l}2.1 / 3.1 / 3.3 \\
4.3 / 4.4\end{array}$ \\
\hline
\end{tabular}

\section{Profissionais externos}

\begin{tabular}{|l|l|l|}
\hline Tipo de profissional & Competências necessárias & Participação no projeto \\
\hline Eletricista & Instalação elétrica & $\begin{array}{l}\text { Cabeamento para instalação da rede } \\
\text { de informática }\end{array}$ \\
\hline Técnico de Informática & $\begin{array}{l}\text { Instalação de hardware, equipamentos, } \\
\text { software e rede }\end{array}$ & $\begin{array}{l}\text { - Equipar o laboratório de informática } \\
\text { e a biblioteca com equipamentos e } \\
\text { programas; - Instalação rede } \\
\text { programas e equipamentos } \\
\text { necessários na escola } \\
\text { - Manutenção ao longo do projeto }\end{array}$ \\
\hline Bibliotecária & $\begin{array}{l}\text { Técnicas de leitura e contação de } \\
\text { histórias }\end{array}$ & $\begin{array}{l}\text { Realização de 3 oficinas de leitura e } \\
\text { contação de histórias com técnicas } \\
\text { que visam o estímulo à leitura em } \\
\text { cada ano do projeto. }\end{array}$ \\
\hline
\end{tabular}




\section{Plano Financeiro}

\section{Investimentos (despesas de capital)}

\begin{tabular}{|l|l|l|l|}
\hline Obras e infraestrutura & Ano 1 & Ano 2 & Ano 3 \\
\hline Cabo de rede & & & \\
\hline Equipamentos Informática & 800,00 & 0,00 & 0,00 \\
\hline Total & $1.500,00$ & 0,00 & 0,00 \\
\hline Material permanente & $2.300,00$ & 0,00 & 0,00 \\
\hline & Ano 1 & Ano 2 & Ano 3 \\
\hline Lousa interativa & 0,00 & 0,00 & 0,00 \\
\hline Projetor Multimídia & 0,00 & 890,00 & 0,00 \\
\hline Materiais Pedagógicos Matemática & $2.300,00$ & 0,00 & 0,00 \\
\hline Acervo Literário & $3.781,40$ & 0,00 & 0,00 \\
\hline Softwares educativos & $7.194,90$ & 0,00 & 0,00 \\
\hline Total & 0,00 & 0,00 & 0,00 \\
\hline
\end{tabular}

\section{Despesas correntes}

\begin{tabular}{|l|l|l|l|}
\hline Material de consumo & Ano 1 & Ano 2 & Ano 3 \\
\hline Livros Ata & 131,60 & 0,00 & 0,00 \\
\hline Folhas para painéis & & & \\
\hline Cadernos para reforço & 138,78 & 0,00 & 0,00 \\
\hline Resmas Sulfite A4 & 371,20 & 0,00 & 0,00 \\
\hline Lâmpada Projetor & & & \\
\hline Total & 202,80 & 0,00 & 0,00 \\
\hline Gastos com locomoção & 2277,00 & 0,00 & 0,00 \\
\hline Transporte Bibliotecária & $3.121,32$ & 0,00 & 0,00 \\
\hline Total & Ano 1 & Ano 2 & Ano 3 \\
\hline Serviços de terceiros & 80,00 & 96,80 & 117,28 \\
\hline Eletricista & 80,00 & 96,80 & 117,28 \\
\hline Técnico em Informática & Ano 1 & Ano 2 & Ano 3 \\
\hline Bibliotecária & $2.500,00$ & 0,00 & 0,00 \\
\hline Total & $4.800,00$ & 780,00 & 943,80 \\
\hline
\end{tabular}


Gestão Participativa: o caminho para qualidade

Outros gastos

\begin{tabular}{|l|l|l|l|}
\hline Gastos adicionais & Ano 1 & Ano 2 & Ano 3 \\
\hline Reposição material cozinha & 200,00 & 242,00 & 292,80 \\
\hline Almofadas para a biblioteca & 250,00 & 100,00 & 50,00 \\
\hline Tapete EVA & 137,28 & & \\
\hline Total & 587,28 & 342,00 & 342,80 \\
\hline
\end{tabular}

Recursos totais

\begin{tabular}{|l|l|l|l|l|}
\hline Tipo de item & Ano 1 & Ano 2 & Ano 3 & Total \\
\hline Despesas de Capital & $15.576,30$ & 890,00 & 0,00 & $16.466,30$ \\
\hline Obras e infraestrutura & $2.300,00$ & 0,00 & 0,00 & $2.300,00$ \\
\hline Material permanente & $13.276,30$ & 890,00 & 0,00 & $14.166,30$ \\
\hline Despesas Correntes & $10.851,32$ & 1300,30 & 1573,51 & $13.725,13$ \\
\hline Material de consumo & 3.121 .32 & 0,00 & 0,00 & $3.121,32$ \\
\hline Gastos com locomoção & 80,00 & 6,80 & 117,28 & 294,08 \\
\hline Serviços de terceiros & $7.650,00$ & $1.203,50$ & $1.456,23$ & $10.309,73$ \\
\hline Total de recursos do edital & $26.427,62$ & $2.190,30$ & $1.573,51$ & $30.191,43$ \\
\hline Gastos adicionais & 587,28 & 342,00 & 342,80 & $1.134,80$ \\
\hline Recursos totais & $27.014,90$ & $2.532,30$ & $1.916,31$ & $31.463,51$ \\
\hline
\end{tabular}

O projeto se enquadra na Categoria A do edital Fontes de recursos

Fontes de recursos

\begin{tabular}{|l|l|}
\hline Fonte & Valor \\
\hline PNAE - Programa Nacional de Alimentação Escolar & 734,80 \\
\hline APM - Associação de Pais e Mestres & 537,28 \\
\hline Recursos totais & $1.272,08$ \\
\hline
\end{tabular}

Contrapartida

\begin{tabular}{|l|l|l|l|}
\hline Profissionais & Horas dedicadas ao projeto & Valor médio/hora & $\begin{array}{l}\text { Contrapartida } \\
\text { por profissional }\end{array}$ \\
\hline Hora aula Professores Readapatados & 2.010 horas & 13,41 & $26.954,10$ \\
\hline Hora aula Professores & 1.988 horas & 13,41 & $26.659,08$ \\
\hline Hora - Coordenador Pedagógico & 2.100 horas & 16,50 & $34.650,00$ \\
\hline Hora - Diretor Escolar & 2.150 horas & 20,00 & $43.000,00$ \\
\hline Hora - Secretária & 1.988 horas & 8,00 & $15.904,00$ \\
\hline Hora - Cozinheiras & 1.988 horas & 7,90 & $15.705,20$ \\
\hline Hora - Inspetores & 1.988 horas & 6,83 & $13.578,04$ \\
\hline Hora - Auxiliares Limpeza & 1.988 horas & 4,90 & $9.741,20$ \\
\hline Total de contrapartida & 16.200 horas & - & $186.191,62$ \\
\hline
\end{tabular}

